\title{
Central Proinflammatory Cytokines and Pain Enhancement
}

\author{
Julie Wieseler-Frank Steven F. Maier Linda R. Watkins \\ Department of Psychology and Center for Neuroscience, University of Colorado at Boulder, Boulder, Colo., USA
}

\begin{abstract}
Key Words
Astrocyte - Microglia • Interleukin-1 • Interleukin-6 •

Tumor necrosis factor-alpha · Sickness behavior •

Proinflammatory cytokines · Allodynia - Hyperalgesia •

Pain facilitation
\end{abstract}

\begin{abstract}
Enhanced pain is a component of the 'sickness response' which is an evolutionarily adaptive constellation of responses that enhance the survival of the host. Proinflammatory cytokines mediate these sickness behaviors, and whether proinflammatory cytokines are involved in exaggerated pain has become an intriguing question. Studies suggest that spinal cord glial cells (astrocytes and microglia) are activated in conditions that lead to enhanced pain. Not only is glial activation associated with enhanced pain, but it is also integral to the induction and maintenance of these pain states. Proinflammatory cytokines can be released by activated astrocytes and microglia within the central nervous system. This review will discuss the role of proinflammatory cytokines in experimental models of prolonged pain states. Administration of exogenous proinflammatory cytokines facilitates pain, and agents that antagonize proinflammatory cytokine actions have been shown to block and/or reverse
\end{abstract}

enhanced pain. These findings suggest that blocking the synthesis and/or release of proinflammatory cytokines may be viable strategies for the treatment of pathological pain. Gene therapy to augment the endogenous antiinflammatory cytokine, interleukin-10, is one of the more promising therapies currently under study.

Copyright $\subset 2005$ S. Karger AG, Basel

\section{Introduction}

Hypersensitivity to nociceptive input is a behavioral consequence of injury or inflammation (for reviews, see $[1,2])$ and is mediated by abnormal neuronal activity associated with the injury or inflammation. Inflammatory mediators released from activated glial cells within the peripheral or central nervous system may play an integral role in driving such abnormal pain state. Conventionally, glia are considered merely as supportive cells for neurons $[3,4]$. However, activated glia release classical immune products including excitatory amino acids, nitric oxide, prostaglandins and proinflammatory cytokines that can all modulate neuronal activity. We propose that these glially derived substances act locally on nearby neurons to drive and maintain chronic exaggerated pain states. Here we will first review the history that led to the discovery of

\section{KARGER}

(C) 2005 S. Karger AG, Basel

Fax +41613061234

E-Mail karger@karger.ch

www.karger.com
Accessible online at: www.karger.com/nsg
Dr. Julie Wieseler-Frank

Department of Psychology, Campus Box 345

University of Colorado at Boulder

Boulder, CO 80309-0345 (USA)

Tel. +1 303735 2295, Fax +1 303492 2967, E-Mail frankjw@psych.colorado.edu 
glial involvement in enhanced pain states. Glial physiology and the current knowledge regarding the role of glia in pain regulation will be discussed. Finally, we will discuss the clinical potential for translating this basic science research into new therapies for chronic pain.

\section{Historical Overview}

While excitatory amino acids, nitric oxide, and prostaglandins have long been implicated in spinally mediated pain facilitation, proinflammatory cytokines have not. Indeed, the earliest hints that CNS proinflammatory cytokines may modulate pain did not even derive from studies of pain. Rather, they derived from studies aimed at understanding how the CNS organizes a wide-ranging constellation of changes, all triggered by peripheral immune challenge. These evolutionarily old, phylogenetically ubiquitous 'sickness responses' include physiological changes (fever, increased white blood cell count, alterations in blood carrier proteins and ions, increased sleep), endocrine changes (e.g. activation of the hypothalamo-pituitary axis and the sympathetic nervous system) and behavioral changes (e.g. decreased social interaction, decreased exploration, decreased sexual activity, loss of dominance in social hierarchies, decreased food and water intake) [5-8]. Sickness responses have been argued to be survival-oriented as they decrease extraneous energy use and increase endogenous energy production, so to facilitate the organism's ability to generate fever [7]. Fever, in turn, enhances survival by simultaneously hindering replication of pathogens and stimulating the replication of the host's white blood cells.

Belatedly, pain facilitation was recognized and accepted as an integral component of the sickness response [9, 10]. The timing of the discovery of sickness-induced hyperalgesia was fortuitous [9] as a large body of evidence had by then accrued which illuminated the CNS mechanisms underlying sickness responses. Critically, what these studies demonstrated was that proinflammatory cytokines, derived in large part from glia, were key mediators in the induction and maintenance of every sickness response examined [5, 11, 12]. This, in turn, logically predicted that spinal cord glia and glially-derived proinflammatory cytokines would ultimately be proven to be key mediators of sickness-induced pain enhancement as well.

This prediction turned out to be true. That is, proinflammatory cytokines and glial activation were indeed implicated in sickness-induced enhanced pain responses [13-16]. It should be emphasized here that sickness-in- duced pain enhancement is physiological, not pathological. It is a naturally initiated and naturally resolved alteration in organismic functioning, with widespread evolutionary and phylogenetic precedence.

So, how does a normal, physiological response to immunologic challenge map onto pathological pain? This is an intriguing and only partially understood issue. One, admittedly partial, answer is that there is simply more than one way to activate glia. A 'normal', 'physiological' way of activating glia involved in pain regulation is via sickness-induced activation of immune-to-brain-to-spinal-cord circuitry $[17,18]$. However, if the end product of spinal cord glial activation is pain enhancement, this in turn predicts that anything that activates these cells could potentially create pain enhancement as well. This raises the possibility that spinal inflammation, central or peripheral trauma, or other non-physiologic event could also tap into and activate this ancient survival pain-enhancing circuit. And they do. The evidence for this conclusion will be summarized in sections that follow.

Before proceeding further, a parallel history bears note. Fascinatingly, a completely independent line of research led to the same prediction that glia were going to be key players in pain facilitation. The early literature from the 1970s and 1980s was again completely disparate from pain. This literature was focused on understanding the observation that peripheral nerve damage led to CNS glial activation. Trauma to peripheral motor nerves led to glial activation around the axotomized motor neurons; trauma to peripheral sensory nerves led to glial activation in the region of degenerating central terminals [19-23]. It wasn't until the early-to-mid-1990s that Garrison et al. [24] made the first links between nerve damage-induced pain facilitation and nerve damage-induced glial activation. They examined the immunohistochemical expression of the astrocyte-specific activation marker, glial fibrillary acidic protein (GFAP), in spinal cords of rats that had undergone sciatic chronic constriction injury (CCI) versus sham surgery. They found that: (1) CCI, which creates exaggerated pain, activates astrocytes, and (2) a pharmacological manipulation that blocks exaggerated pain also blocks astrocyte activation [25]. Since then, every animal model of pain facilitation that has been studied has revealed a positive correlation between exaggerated pain responses and glial activation in the spinal cord. As will be discussed below, this relationship between glial activation and exaggerated pain responses is of interest here because, within the spinal cord, activated glial cells can release proinflammatory cytokines as well as a variety of downstream neuroexcitatory substances. 


\section{Understanding Glia}

The term glia is used here to refer to both microglia and astrocytes. As described below, both cell types are activated by the same kinds of stimuli and both are activated in response to experimental manipulations that induce pain amplification. Both cell types, upon activation, can produce and release a variety of pain-enhancing substances. In addition, each stimulates the further activation of the other. Indeed these cells are able to work in a tandem to produce neuroexcitatory products. Use of the term 'glia' here reflects currently available data showing that both microglia and astrocytes are involved in exaggerated pain. The relative contribution that each glial cell type makes to pain facilitation is a topic of ongoing investigation.

Before proceeding with a discussion of how glia may modulate pain, it is important to understand some basics about glial physiology. Under normal conditions, glia are in a resting state. For astrocytes, this means regulating extracellular ion and neurotransmitter concentrations, availability of neurotransmitter/neuromodulator precursors to nearby neurons [26], and extracellular $\mathrm{pH}$ [27]. In other words, in a basal state, astrocytes are involved in maintaining homeostasis in their respective microenvironments. On the other hand, microglia are quiescent with no recognized function while they are in this resting state [28]. The morphology of resting astrocytes and microglia is dramatically different from that of activated microglia and astrocytes. Basal astrocytes have many thin processes. Resting microglia also have many thin processes with a ramified morphology, and little to no receptor expression or activity associated with an activated cell.

Astrocytes and microglia become activated in response to CNS trauma, ischemia, tumors, neurodegeneration, viruses, and bacteria. Notably, glia can become activated in response to neurotransmitters and neuromodulators as well. Activation of astrocytes is characterized morphologically as hypertrophy and increased production of intermediate filaments (GFAP, vimentin and/or nestin), and functionally as an increased production of proinflammatory substances [29]. Activation of microglia is also characterized by morphological changes. As microglia become increasingly activated, the microglial processes gradually shorten and become plumper, and with stronger stimulation a complete retraction of processes and an amoeboid morphology is observed [28]. In addition to morphological changes, activated microglia proliferate, increase expression of one or more cell surface markers or receptors (including complement 3 receptor associated with adhesion, migration and phagocytosis) and/or exhibit changes in functional activities, such as migration to areas of injury, phagocytosis, and the production/release of proinflammatory substances. For both astrocytes and microglia, morphological and functional changes are not necessarily linked. In other words, functional changes can occur before the increases in intermediate filaments, and vice versa. Morphological changes do not necessarily imply which, if any, substances the cells are releasing. For both cell types, the manner in which activation is expressed is dependent upon the type and intensity of the stimulus. Thus, different patterns and time courses of responses can occur.

Glial function and responsivity within the CNS in general, and within the spinal cord in particular, is highly dependent on the local microenvironment. Spinal cord glia can express receptors not found on glia in many other CNS regions, and/or they can express receptors in a region-dependent manner within the spinal cord. For example, the spinal cord is one of the few CNS sites where glia express receptors for substance P [30]. Within the spinal cord, the receptor for the neuron-to-glia signal, fractalkine, is most densely expressed by microglia in the superficial dorsal horn and this receptor expression is modulated by peripheral nerve injury [31]. Similarly, the gap junctional protein, connexin 43 , is expressed predominately by astrocytes in the spinal cord, is most concentrated in superficial dorsal horn, and its activation state in superficial dorsal horn is altered by peripheral nerve injury [32]. Decreases in glial glutamate transporter expression and increases in microglial cyclooxygenase1 expression have also been observed, specifically in superficial dorsal horn, following trauma to peripheral tissues $[33,34]$. Thus, while this line of investigation is still in its infancy, it is already clear that further studies of dorsal horn glial receptor expression and regulation is warranted.

\section{Glia and Pain}

The observation that astrocytes and microglia are activated under conditions associated with enhanced pain responses suggests, but does not prove, glial regulation of pain. Intrathecal administration of glial-specific inhibitors has been used to show that glial activation is necessary for pain facilitation. Fluorocitrate is a general glial inhibitor that blocks activity of both astrocytes and microglia. The pharmacology of fluorocitrate takes advan- 
tage of the fact that only glia (not neurons) take up extracellular citrate for metabolism in the Krebs cycle [35]. Glia also take up fluorocitrate, which is substituted for citrate in the Krebs cycle. Once fluorocitrate is inside the cell, it acts to block the activity of aconitase, a Krebs cycle enzyme that converts citrate to isocitrate. At low doses, the actions of fluorocitrate on glia are nontoxic and reversible [36]. At higher doses, fluorocitrate becomes toxic to glia and because of its actions on glia, it can indirectly alter neuronal activity. Studies using fluorocitrate as a glia activity inhibitor explicitly use low doses and short post-drug periods to avoid potential confounds of effects on neurons secondary to the shutdown of glia. Diverse pain states, including those induced by chronic sciatic inflammatory neuropathy [37], intrathecal viral components [38, 39], subcutaneous formalin [13], and intraplantar zymosan [40], are all blocked and/or reversed by intrathecal fluorocitrate.

A second, more targeted, method for analyzing glial involvement in pain is the use of minocycline. Minocycline is a semisynthetic, second-generation tetracycline derivative that selectively inhibits microglial activity independent of its antibiotic effects [41-43]. It inhibits proinflammatory responses by immune cells, including inhibition of matrix metalloproteases [44], suppression of neutrophil respiratory bursts $[45,46]$, inhibition of inducible nitric oxide synthase (iNOS) gene expression [47, 48], and inhibits scavenging of peroxynitrite [49]. As a result of such actions, clinical studies indicate that minocycline may be beneficial in the treatment of rheumatoid arthritis and, potentially, other inflammatory diseases [50, 51]. Raghavendra et al. [52] found that pre-emptive systemic administration of minocycline suppressed the synthesis and release of spinal cord proinflammatory cytokines in response to peripheral nerve transection. Moreover, Raghavendra et al. [52] and Ledeboer et al. [53] found that administration of minocycline blocks the development of exaggerated pain. Thus, microglial activation is necessary for the development of such pain states. Intriguingly, minocycline failed to reverse [52], or only weakly reversed [53], established chronic pain. The minocycline data are intriguing as they point to potentially distinct roles for microglia and astrocytes in the initiation and maintenance of exaggerated pain responses. Furthermore, minocycline, while unable to reverse established neuropathic pain behavior, still inhibited microglial activity while not affecting astrocyte activity [52]. These data have led to the proposal that early microglial activation leads in turn to activation of astrocytes, and that astrocyte activation serves to maintain pain neuropathic pain states. Taken together, these data suggest that microglia, and proinflammatory products released by activated microglia, are necessary for the induction of exaggerated pain, but that the maintenance of enhanced pain responses over time is created by enduring astrocyte activation.

It is important to note another key finding from the glial inhibitor studies that will be further substantiated in studies reviewed below. That is, glia do not appear to be involved in basal pain responsivity. Blocking glial activation with fluorocitrate [37-40], blocking microglial activation with minocycline [52,53], and (as will be reviewed below) blocking glial proinflammatory cytokine actions $[13,37,38]$ have no observable effect on basal responses to mechanical or thermal stimuli. While one study has demonstrated decreased basal pain responsivity in IL-1 knockout mice, these changes appear to reflect alterations created by absence of IL-1 during development, rather than an effect of IL-1 on basal pain responsivity in the adult organism [54].

A last issue here is whether glial activation is not simply necessary for pain enhancement, but rather whether it is also sufficient. One strategy for selective glial activation in vivo rests on the fact that glia (but not neurons) are immunocompetent cells. That is, while astrocytes and possibly even microglia are not of immune cell origin [55], they do still express receptors for foreign invaders such as viruses and bacteria. Therefore, to directly activate spinal cord glia, the portions of bacteria and viruses that bind to and activate glia have been used [38-40]. The resultant glial activation does indeed induce exaggerated pain responses, which can be blocked by the glial inhibitor, fluorocitrate [38]. Thus, glial activation can be sufficient for creating pain facilitation. Tsuda et al. [56] have recently published evidence that further points to glial activation being sufficient to induce enhanced pain responses. In this study, microglia were activated in cell culture and then injected intrathecally into naïve animals. Upon injection, the activated microglia induced mechanical allodynia. Taken together, the studies reviewed above provide converging evidence that glial activation can be sufficient for the induction of enhanced pain responsivity.

\section{Proinflammatory Cytokines}

The sections above have repeatedly referred to proinflammatory cytokines (tumor necrosis factor [TNF], interleukin-1 [IL-1], and interleukin-6 [IL-6]). Given that 
these signaling proteins are not classically thought of as pain modulators, a further description of this cytokine family is warranted here. In classical immunology, these proteins have been associated with cell proliferation, differentiation, and changes in gene expression [57], and synthesis of matrix proteins important to cell growth and tissue repair [58]. In addition, they are essential in fighting infection and responding to injury. It is in this role that these cytokines came to be termed 'pro-inflammatory' as they orchestrate the early immune response to infection/injury by recruiting immune cells to the site and activating them. These proteins are often released in a cascade, where an initial release of TNF is followed first by IL- 1 and then by IL-6. These proinflammatory cytokines are uniquely powerful. It has been estimated that less than 10 IL-1 receptors have to be occupied to induce a physiological response $[59,60]$. Indeed, if proinflammatory cytokine release/activity is left unchecked, this can lead to damage of host tissue as well as pathogens [61]. Because of this danger, the synthesis and release of proinflammatory cytokines is tightly regulated with numerous negative feedback control systems in place including the production of anti-inflammatory cytokines, 'decoy' receptors, and endogenous proinflammatory cytokine receptor antagonists. Under normal circumstances, these negative feedback controls help suppress the production and function of proinflammatory cytokines when proinflammatory cytokine action is no longer required.

In spinal cord, each of these proinflammatory cytokines has been implicated in pain facilitation. Proinflammatory cytokines activate neurons as well as glia via binding to specific receptors. Thus this is a means by which glia can signal neurons as well as other glia. TNF, IL-1 and/or IL-6 mRNA expression is elevated in spinal cord in response to peripheral nerve injury [62], spinal nerve injury $[63,64]$ or intrathecal injection of viral components [65], each of which induces enhanced pain responses. TNF, IL-1 and/or IL-6 proteins are elevated in spinal cord following peripheral nerve injury [66-69], spinal nerve injury [52], subcutaneous formalin and zymosan [70], or intrathecal viral components [38, 39, 65]. Importantly, TNF, IL-1 and IL-6 protein release into lumbar cerebrospinal fluid has been observed under conditions of pain facilitation [38]. Documentation of cytokine release is important since proinflammatory cytokines have been reported to increase intracellularly in the absence of release. Hence, the observation of elevated proinflammatory cytokine levels in spinal tissue does not necessarily imply that the cytokines were released so to exert downstream effects.
The increase of proinflammatory cytokines in animal models of pain facilitation suggests, but does not prove, that they play a significant role in the creation and/or the maintenance of exaggerated pain states. If this were true, then peri-spinal administration of proinflammatory cytokines should induce exaggerated pain, and blocking the central activity of these cytokines should block or reverse exaggerated pain responses. Indeed, perispinal administration of exogenous IL-6 [67] or IL-1 [71, 72] induces mechanical allodynia and/or thermal hyperalgesia, and perispinal administration of IL-1 has been shown to enhance neuronal excitability to noxious stimuli $[72,73]$. Intrathecal administration of TNF antagonist (TNFbinding protein, also called TNF-soluble receptors; TNFsr) blocks and/or reverses the pain-enhancing effects of peripheral immune activation [17], spinal nerve transection [74], and sciatic inflammatory neuropathy [37]. Similarly, intrathecal IL-1 receptor antagonist (IL-1 ra) blocks and/or reverses the pain-enhancing effects of subcutaneous formalin [13], intrathecal dynorphin [75], intrathecal viral components [38], sciatic inflammation [37], and CCI [76]. Finally, blocking spinal IL-6 activity with anti-rat IL-6 neutralizing antibody has been shown to block and/or reverse the pain-enhancing effects of sciatic inflammatory neuropathy [37], and spinal nerve transection [77].

Why blocking each of these cytokines individually can each block/reverse enhanced pain responses may at first glance appear illogical. However, two points are worth noting here. First, the effects of proinflammatory cytokines can strongly synergize where in combination they exert powerful effects not seen upon application of any one alone [61]. Hence, blocking any single cytokine would be anticipated to disrupt such synergistic actions. Second, proinflammatory cytokines often stimulate each other's production [38].

\section{Why Is This Important?}

If one accepts at face value that glia, and their proinflammatory products, are key players in the creation and maintenance of pain facilitation, then how might one apply this knowledge toward clinical pain control? Laboratory animal studies have successfully utilized a wide array of drugs to control glial activation and their proinflammatory products. Thus the question arises whether any of these, or related compounds, might be feasible for consideration for human use to control chronic pain [78]. Based on animal studies, one potentially logical pharma- 
cological agent might be assumed to be fluorocitrate, given that it inhibits astrocyte and microglial activity. However, as noted above, fluorocitrate can only be assumed to selectively affect glia when testing occurs at short time intervals after low doses of this compound [35]. At longer postdrug intervals and higher doses, neurons are indirectly affected by the rising levels of excitatory amino acids due to inhibition of glial excitatory amino acid transport. Indeed, reflective of this indirect effect on neurons, seizures have also been reported in response to gliatoxic doses of this compound [79].

Administration of the microglial inhibitor, minocycline, may also seem plausible, given its ability to block the initiation of various enhanced pain states. However, as noted above, this compound has far less efficacy in reversing already established pain states, at least in animal models. If this profile were to occur in humans, it would predict that the drug would not be useful for reversing chronic pain. As such, its clinical usefulness appears severely limited.

Another approach may be to block the release of neuroactive products from activated glia by administering compounds such as propentofylline. Propentofylline appears very promising based on the fact that it can both prevent and reverse enhanced pain states via blockade of both microglial and astrocyte activation [80]. Indeed, it has already received FDA approval for other clinical uses.

A different approach is to target specific intracellular pathways involved in proinflammatory cytokine production and signaling. p38 mitogen-activated protein kinase (MAPK) is a key component of one such pathway. p38 MAPK is activated (phosphorylated) in response to immune stimuli and has been reported to be increased in pathological pain models including spinal nerve ligation [81, 82], intraplantar formalin [83] and CCI [83]. Furthermore, p38MAPK is activated by glutamate, a classical pain neurotransmitter [41]. Therefore, one would predict that inhibiting p38MAPK would block proinflammatory cytokines, thereby blocking exaggerated pain. Indeed intrathecal p38 MAPK inhibitors block enhanced pain responses induced by every animal model tested to date, including spinal cord inflammation [39], peripheral nerve inflammation [37], intrathecal substance P [84] and intrathecal NMDA [85].

The newest approach for the treatment of pathological pain is gene therapy coding for the anti-inflammatory cytokine, IL-10. As noted in an introductory paragraph to this article, anti-inflammatory cytokines provide negative feedback to pro-inflammatory production and release. As an anti-inflammatory cytokine, IL-10 selective- ly suppresses proinflammatory cytokine synthesis and release, upregulates the production of other anti-inflammatory substances, and downregulates the expression of proinflammatory cytokine receptors [86]. Thus, it attacks proinflammatory function at multiple levels. This negative feedback prevents the proinflammatory response from leading to pathological states. However, intrathecal administration of IL-10 protein, due to its short half-life, can only transiently (approximately $1-2 \mathrm{~h}$ ) reverse enhanced pain even after large doses [87]. Hence, given the chronic nature of pathological pain, this approach is not a cost-effective option. In contrast, intrathecally administering the IL-10 gene in a vector allows regional cells to take up the vector and synthesize IL-10 over a prolonged time [87]. By inducing the production of this anti-inflammatory cytokine, one should be able to prevent proinflammatory cytokine production at the level of transcription, translation, and release; inhibit proinflammatory cytokine receptor expression plus increase the production of other anti-inflammatory mediators (e.g. IL-4, IL-13) so to further block proinflammatory cytokine activity. IL-10 is even more attractive because IL-10 receptors, to date, have not been found on spinal neurons [88]. If these early data are replicated, then this predicts that intrathecal IL-10 would act only on glia, leaving neuronal function unaffected. Even in brain, the only reported effect of IL10 on neurons is blockade of neuronal death (apoptosis), again suggestive that IL-10 may not exert negative effects on neurons. Indeed, gene therapy to induce spinal IL-10 production has been able to prevent or reverse exaggerated pain in every model tested to date $[76,78,87]$ and recent modifications of this procedure allow prolonged resolution of neuropathic pain $[78,89]$. Taken together, these studies support that IL-10 gene therapy may provide an effective and novel approach for the control of chronic pain.

\section{Concluding Remarks}

In summary, a key role of glia in pain modulation was predicted over 25 years ago by two independent lines of investigation, one examining the survival-oriented sickness responses induced by peripheral immune challenge and the other examining glial activation after peripheral nerve injury. Neither of these research lines originally considered pain facilitation as a natural aftermath of the phenomena under study. However, evidence has accrued, with increasing rapidity, over the past decade that supports a key role of glia and their proinflammatory prod- 
ucts in the creation and maintenance of pathological pain states. This literature, arising from multiple laboratories using diverse animal models, in turn predicts that glial activation and their proinflammatory products provide a novel therapeutic target for the control of clinical pain [78].

\section{Acknowledgements}

This work was supported by NIH grants AI051093, DA015642, DA015656, NS40696 and NS38020.

\section{References}

-1 Watkins LR, Maier SF: Beyond neurons: evidence that immune and glial cells contribute to pathological pain states. Physiol Rev 2002;82: 981-1011.

2 Willis WDJ (ed): Hyperalgesia and Allodynia. New York, Raven Press, 1992.

$\checkmark 3$ Barres BA: New roles for glia. J Neurosci 1991; 11:3685-3694.

-4 Barres BA, Barde Y: Neuronal and glial cell biology. Curr Opin Neurobiol 2000;10:642648.

5 Maier, SF, Watkins LR: Cytokines for psychologists: implications of bidirectional immuneto-brain communication for understanding behavior, mood, and cognition. Psychol Rev 1998; 105:83-107.

-6 Hart BL: Behavior of sick animals. Vet Clin N Am Food Anim Pract 1987;3:383-391.

7 Hart BL: Biological basis of the behavior of sick animals. Neurosci Biobehav Rev 1988;12: 123-137.

$>8$ Kent S, Bluthe RM, Kelley KW, Dantzer R: Sickness behavior as a new target for drug development. Trends Pharmacol Sci 1992;13: 24-28.

9 Maier SF, Wiertelak EP, Watkins LR: Endogenous pain facilitatory systems: anti-analgesia and hyperalgesia. Am Pain Soc J 1992;1:191198

10 Watkins LR, Maier SF: The pain of being sick: implications of immune-to-brain communication for understanding pain. Annu Rev Psychol 2000;51:29-57.

-11 McCarthy DO, Kluger MJ, Vander AJ: Effect of centrally administered interleukin-1 and endotoxin on food intake of fasted rats. Physiol Behav 1986;36:745-749.

$\checkmark 12$ Rothwell NJ: Central effects of TNF alpha on thermogenesis and fever in the rat. Biosci Rep 1988;8:345-352.

13 Watkins LR, Martin D, Ulrich P, Tracey KJ, Maier SF: Evidence for the involvement of spinal cord glia in subcutaneous formalin induced hyperalgesia in the rat. Pain 1997;71:225235.

14 Watkins LR, Goehler LE, Relton JK, Tartaglia N, Silbert L, Martin D, Maier SF: Blockade of interleukin-1 induced hyperthermia by subdiaphragmatic vagotomy: evidence for vagal mediation of immune-brain communication. Neurosci Lett 1995; 183:27-31.
15 Maier SF, Wiertelak EP, Martin D, Watkins LR: Interleukin-1 mediates the behavioral hyperalgesia produced by lithium chloride and endotoxin. Brain Res 1993;623:321-324.

16 Watkins LR, Maier SF, Goehler LE: Immune activation: the role of pro-inflammatory cytokines in inflammation, illness responses and pathological pain states. Pain 1995;63:289302 .

17 Watkins LR, Wiertelak EP, Goehler LE, Mooney-Heiberger K, Martinez J, Furness L, Smith KP, Maier SF: Neurocircuitry of illnessinduced hyperalgesia. Brain Res 1994;639: 283-299.

18 Wiertelak EP, Roemer B, Maier SF, Watkins LR: Comparison of the effects of nucleus tractus solitarius and ventral medial medulla lesions on illness-induced and subcutaneous formalin-induced hyperalgesias. Brain Res 1997; 748:143-150

19 Graeber MB, Streit WJ, Kreutzberg GW: Axotomy of the rat facial nerve leads to increased CR3 complement receptor expression by activated microglial cells. J Neurosci Res 1988;21: 18-24.

20 Hajos F, Csillik B, Knyihar-Csillik E: Alterations in glial fibrillary acidic protein immunoreactivity in the upper dorsal horn of the rat spinal cord in the course of transganglionic degenerative atrophy and regenerative proliferation. Neurosci Lett 1990;117:8-13.

21 Hall LL, Borke RC, Anders JJ: Transection or electrical stimulation of the hypoglossal nerve increases glial fibrillary acidic protein immunoreactivity in the hypoglossal nucleus. Brain Res 1989;490:157-161.

22 Sjostrand J: Neuroglial proliferation in the hypoglossal nucleus after nerve injury. Exp Neurol 1971;30:178-189.

23 Tetzlaff W, Graeber MB, Bisby MA, Kreutzberg GW: Increased glial fibrillary acidic protein synthesis in astrocytes during retrograde reaction of the rat facial nucleus. Glia 1988; 90-95.

-24 Garrison CJ, Dougherty PM, Kajander KC Carlton SM: Staining of glial fibrillary acidic protein (GFAP) in lumbar spinal cord increases following a sciatic nerve constriction injury. Brain Res 1991;565:1-7.

25 Garrison CJ, Dougherty PM, Carlton SM: GFAP expression in lumbar spinal cord of naive and neuropathic rats treated with MK-801. Exp Neurol 1994;129:237-243.
26 Schousboe A, Westergaard N: Transport of neuroactive amino acids in astrocytes; in Kettenmann H, Ransom BR (eds): Neuroglia. New York, Oxford University Press, 1995, pp 246-258.

27 Ransom BR: Glial modulation of neural excitability mediated by extracellular $\mathrm{pH}$ : a hypothesis. Prog Brain Res 1992;94:37-46.

-28 Kreutzberg GW: Microglia: a sensor for pathological events in the CNS. Trends Neurosci 1996;19:312-318.

29 Ridet JL, Malhotra SK, Privat A, Gage FH: Reactive astrocytes: cellular and molecular cues to biological function. Trends Neurosci 1997;20:570-577.

30 Marriott DR, Wilkin GP, Wood JN: Substance $\mathrm{P}$-induced release of prostaglandins from as trocytes: regional specialisation and correlation with phosphoinositol metabolism. J Neurochem 1991;56:259-265.

31 Verge G, Milligan ED, Twining C, Maier SF, Watkins LR, Foster AC, Naeve GS: Mapping fractalkine and its receptor (CX3CR1) in a rat model of sciatic inflammatory neuropathy (SIN). Proc Soc Neurosci 2002;28.

32 Ochalski, PA, Frankenstein UN, Hertzberg EL, Nagy JI: Connexin-43 in rat spinal cord: localization in astrocytes and identification of heterotypic astro-oligodendrocytic gap junctions. Neuroscience 1997;76:931-945.

33 Zhu X, Conklin D, Eisenach JC: Cyclooxygenase- 1 in the spinal cord plays an important role in postoperative pain. Pain 2003;104:15-23.

34 Zhu X, Eisenach JC: Cyclooxygenase-1 in the spinal cord is altered after peripheral nerve injury. Anesthesiology 2003;99:1175-1179.

35 Fonnum F, Johnsen A, Hassel B: Use of fluorocitrate and fluoroacetate in the study of brain metabolism. Glia 1997;21:106-113.

36 Paulsen RE, Contestabile A, Villani L, Fonnum F: An in vivo model for studying function of brain tissue temporarily devoid of glial cell metabolism: the use of fluorocitrate. J Neurochem 1987:48:1377-1385.

37 Milligan ED, Twining C, Chacur M, Biedenkapp J, O'Connor K, Poole S, Tracey K, Martin D, Maier SF, Watkins LR: Spinal glia and proinflammatory cytokines mediate mirrorimage neuropathic pain in rats. $\mathrm{J}$ Neurosci 2003;23:1026-1040. 
\38 Milligan ED, O'Connor KA, Nguyen KT, Armstrong CB, Twining C, Gaykema RP, Holguin A, Martin D, Maier SF, Watkins LR: Intrathecal HIV-1 envelope glycoprotein gp120 induces enhanced pain states mediated by spinal cord proinflammatory cytokines. J Neurosci 2001;21:2808-2819.

-39 Milligan ED, Mehmert KK, Hinde JL, Harvey LO, Martin D, Tracey KJ, Maier SF, Watkins LR: Thermal hyperalgesia and mechanical allodynia produced by intrathecal administration of the human immunodeficiency virus-1 (HIV-1) envelope glycoprotein, gp120. Brain Res 2000;861:105-116.

-40 Meller ST, Dykstra C, Grzybycki D, Murphy S, Gebhart GF: The possible role of glia in nociceptive processing and hyperalgesia in the spinal cord of the rat. Neuropharmacology 1994;33:1471-1478.

-41 Tikka TM, Koistinaho JE: Minocycline provides neuroprotection against $\mathrm{N}$-methyl- $D$-aspartate neurotoxicity by inhibiting microglia. J Immunol 2001;166:7527-7533.

-42 Tikka T, Fiebich BL, Goldsteins G, Keinanen R, Koistinaho J: Minocycline, a tetracycline derivative, is neuroprotective against excitotoxicity by inhibiting activation and proliferation of microglia. J Neurosci 2001;21:2580 2588.

43 Aronson AL: Pharmacotherapeutics of the newer tetracyclines. J Am Vet Med Assoc 1980;176:1061-1068.

-44 Golub LM, Ramamurthy NS, McNamara TF, Greenwald RA, Rifkin BR: Tetracyclines inhibit connective tissue breakdown: new therapeutic implications for an old family of drugs. Crit Rev Oral Biol Med 1991;2:297-321.

45 Gabler WL, Creamer HR: Suppression of human neutrophil functions by tetracyclines. $\mathrm{J}$ Periodontal Res 1991;26:52-58.

46 Gabler WL, Smith J, Tsukuda NL: Comparison of doxycycline and a chemically modified tetracycline inhibition of leukocyte functions. Res Commun Chem Pathol Pharmacol 1992; 78:151-160.

47 Amin AR, Attur MG, Thakker GD, Patel PD Vyas PR, Patel RN, Patel IR, Abramson SB: A novel mechanism of action of tetracyclines: effects on nitric oxide synthases. Proc Natl Acad Sci USA 1996;93:14014-14019.

-48 Amin AR, Patel RN, Thakker GD, Lowenstein CJ, Attur MG, Abramson SB: Post-transcriptional regulation of inducible nitric oxide synthase mRNA in murine macrophages by doxycycline and chemically modified tetracyclines. FEBS Lett 1997;410:259-264.

49 Whiteman M, Halliwell B: Prevention of peroxynitrite-dependent tyrosine nitration and inactivation of alpha1-antiproteinase by antibiotics. Free Radic Res 1997;26:49-56.

50 O'Dell JR, Blakely KW, Mallek JA, Eckhoff PJ, Leff RD, Wees SJ, Sems KM, Fernandez AM, Palmer WR, Klassen LW, Paulsen GA, Haire CE, Moore GF: Treatment of early seropositive rheumatoid arthritis: a two-year, double-blind comparison of minocycline and hydroxychloroquine. Arthritis Rheum 2001;44: 2235-2241.
Kloppenburg M, Breedveld FC, Terwiel JP, Mallee C, Dijkmans BA: Minocycline in active rheumatoid arthritis: a double-blind, placebocontrolled trial. Arthritis Rheum 1994;37: 629-636.

-52 Raghavendra V, Tanga F, DeLeo JA: Inhibition of microglial activation attenuates the development but not existing hypersensitivity in a rat model of neuropathy. J Pharmacol Exp Ther 2003;306:624-630.

53 Ledeboer A, Sloane E, Chacur M, Milligan ED, Maier SF, Watkins LR: Selective inhibition of spinal cord microglial activation attenuates mechanical allodynia in rat models of pathological pain. Proc Soc Neurosci 2003;29:in press.

54 Wolf G, Yirmiya R, Goshen I, Iverfeldt K, Holmlund L, Takeda K, Shavit Y: Impairment of interleukin-1 (IL-1) signaling reduces basal pain sensitivity in mice: genetic, pharmacological and developmental aspects. Pain 2003; 104:471-480.

55 Fedoroff S: Development of microglia; in Kettenmann H, Ransom BR (eds): Neuroglia. New York, Oxford University Press, 1995, pp 162-181.

56 Tsuda M, Shigemoto-Mogami Y, Koizumi S, Mizokoshi A, Kohsaka S, Salter MW, Inoue K P2X4 receptors induced in spinal microglia gate tactile allodynia after nerve injury. Nature 2003; 424:778-783.

57 Janeway CA, Travers P, Walport M, Shlomchik M: Immunobiology, ed 5. Garland Publishing, New York, 2001.

58 Mauviel A: Cytokine regulation of metalloproteinase gene expression. J Cell Biochem 1993; 53:288-295.

59 Gallis B, Prickett KS, Jackson J, Slack J, Schooley K, Sims JE, Dower SK: IL-1 induces rapid phosphorylation of the IL-1 receptor. J Immunol 1989; 143:3235-3240.

60 Dinarello CA: Interleukin-1. Cytokine Growth Factor Rev 1997;8:253-265.

61 Dinarello CA: Proinflammatory cytokines. Chest 2000;118:503-508.

62 Arruda JL, Colburn RW, Rickman AJ, Rutkowski MD, DeLeo JA: Increase of interleukin-6 mRNA in the spinal cord following peripheral nerve injury in the rat: potential role of IL-6 in neuropathic pain. Brain Res Mol Brain Res 1998;62:228-235.

63 Winkelstein BA, Rutkowski MD, Weinstein JN, DeLeo JA: Quantification of neural tissue injury in a rat radiculopathy model: comparison of local deformation, behavioral outcomes, and spinal cytokine mRNA for two surgeons. J Neurosci Methods 2001:111:49-57.

64 Winkelstein BA, Rutkowski MD, Sweitzer SM, Pahl JL, DeLeo JA: Nerve injury proximal or distal to the DRG induces similar spinal glial activation and selective cytokine expression but differential behavioral responses to pharmacologic treatment. J Comp Neurol 2001; 439:127-139.
65 Holguin A, O'Connor K, Hansen MK, Milligan ED, Cheepsunthorn P, Braymann C, Cochran K, Biedenkapp J, Martin D, Maier SF, Watkins LR: HIV-1 gp120-induced spinal proinflammatory cytokine production and low threshold mechanical allodynia are mediated by nitric oxide. Brain Behav Immun 2002;16: 191.

66 Winkelstein BA, DeLeo JA: Nerve root injury severity differentially modulates spinal glial activation in a rat lumbar radiculopathy model: considerations for persistent pain. Brain Res 2002;956:294-301

67 DeLeo JA, Colburn RW, Nichols M, Malhotra A: Interleukin-6-mediated hyperalgesia/allodynia and increased spinal IL-6 expression in a rat mononeuropathy model. J Interferon $\mathrm{Cy}$ tokine Res 1996;16:695-700.

68 Hashizume H, DeLeo JA: Colburn RW, Weinstein JN: Spinal glial activation and cytokine expression after lumbar root injury in the rat. Spine 2000;25:1206-1217.

69 DeLeo JA, Colburn RW, Rickman AJ: Cytokine and growth factor immunohistochemical spinal profiles in two animal models of mononeuropathy. Brain Res 1997;759:50-57.

70 Sweitzer SM, Colburn RW, Rutkowski M, DeLeo JA: Acute peripheral inflammation induces moderate glial activation and spinal ILlbeta expression that correlates with pain behavior in the rat. Brain Res 1999;829:209221.

71 Falchi M, Ferrara F, Gharib CB: Dib, Hyperalgesic effect of intrathecally administered interleukin-1 in rats. Drugs Exp Clin Res 2001; 27:97-101

72 Reeve AJ, Patel S, Fox A, Walker K, Urban L: Intrathecally administered endotoxin or cytokines produce allodynia, hyperalgesia and changes in spinal cord neuronal responses to nociceptive stimuli in the rat. Eur J Pain 2000; 4:247-257.

73 Oka T, Hori T: Brain cytokines and pain; in Watkins LR, Maier SF (eds): Cytokines and Pain. Basel, Birkhäuser, 1999, pp 183-204.

74 Sweitzer S, Martin D, DeLeo JA: Intrathecal interleukin-1 receptor antagonist in combination with soluble tumor necrosis factor receptor exhibits an anti-allodynic action in a rat model of neuropathic pain. Neuroscience 2001;103:529-539.

75 Laughlin TM, Bethea JR, Yezierski RP, Wilcox GL: Cytokine involvement in dynorphininduced allodynia. Pain 2000;84:159-167.

76 Sloane EM, Langer SE, Milligan ED, WieselerFrank J, Mahoney J, Levkoff L, Cruz P, Flotte TR, Leinwant L, Maier SF, Watkins LR: Chronic constriction injury induced pathological pain states are controlled long term via intrathecal administration of a non-viral vector (NVV) encoding the anti-inflammatory cytokine interleukin-10 (IL-10). Proc Am Pain Soc, 2004.

77 Arruda JL, Sweitzer S, Rutkowski MD, DeLeo JA: Intrathecal anti-IL-6 antibody and IgG attenuates peripheral nerve injury-induced mechanical allodynia in the rat: possible immune modulation in neuropathic pain. Brain Res 2000;879:216-225. 
78 Watkins LR, Maier SF: Glia: a novel drug discovery target for clinical pain. Nature Rev Drug Discovery 2003;2:973-985.

79 Hornfeldt CS, Larson AA: Seizures induced by fluoroacetic acid and fluorocitric acid may involve chelation of divalent cations in the spinal cord. Eur J Pharmacol 1990;179:307-313.

80 Sweitzer SM, Schubert P, DeLeo JA: Propentofylline, a glial modulating agent, exhibits antiallodynic properties in a rat model of neuropathic pain. J Pharmacol Exp Ther 2001;297: 1210-1217.

81 Schafers M, Svensson CI, Sommer C, Sorkin LS: Tumor necrosis factor-alpha induces mechanical allodynia after spinal nerve ligation by activation of p38 MAPK in primary sensory neurons. J Neurosci 2003;23:25172521.

-82 Jin SX, Zhuang ZY, Woolf CJ, Ji RR: p38 mitogen-activated protein kinase is activated after a spinal nerve ligation in spinal cord microglia and dorsal root ganglion neurons and contributes to the generation of neuropathic pain. J Neurosci 2003;23:4017-4022.
83 Kim SY, Bae JC, Kim JY, Lee HL, Lee KM, Kim DS, Cho HJ: Activation of p38 MAP kinase in the rat dorsal root ganglia and spinal cord following peripheral inflammation and nerve injury. Neuroreport 2002;13:24832486.

-84 Svensson CI, Marsala M, Westerlund A, Calcutt NA, Campana WM, Freshwater JD, Catalano R, Feng Y, Protter AA, Scott B, Yaksh TL: Activation of p38 mitogen-activated protein kinase in spinal microglia is a critical link in inflammation-induced spinal pain processing. J Neurochem 2003;86:1534-1544.

85 Svensson CI, Hua XY, Protter AA, Powell HC, Yaksh TL: Spinal p38 MAP kinase is necessary for NMDA-induced spinal PGE(2) release and thermal hyperalgesia. Neuroreport 2003;14: 1153-1157.

86 Moore KW, de Waal Malefyt R, Coffman RL, O'Garra A: Interleukin-10 and the interleukin10 receptor. Annu Rev Immunol 2001; 19: 683-765.
87 Milligan ED, Langer SE, Sloane E, Chacur M, Wieseler-Frank J, Frank M, Flotte TR, Cruz P, Leinwand L, Maier SF, Watkins LR: Inflammatory and chronic constriction injury-induced pain states are controlled by spinal delivery of viral and non-viral vectors encoding the anti-inflammatory gene, interleukin-10 (IL10). Proc Soc Neurosci, 2003, p 29.

88 Ledeboer A, Wierinckx A, Bol JG, Floris S, Renardel de Lavalette C, De Vries HE, van den Berg TK, Dijkstra CD, Tilders FJ, van dam AM: Regional and temporal expression patterns of interleukin-10, interleukin-10 receptor and adhesion molecules in the rat spinal cord during chronic relapsing EAE. J Neuroimmunol 2003;136:94-103.

89 Milligan, ED, Langer SE, Sloane E, WieselerFrank J, Frank M, Levkoff L, Mahoney J, Chavez R, Forsayeth J, Cruz P, Flotte TR, Leinwand L, Maier SF, Watkins LR: Gene therapy using naked plasmid DNA coding the anti-inflammatory gene, interleukin-10 (IL10): repeated injections lead to long-term pain control in chronic constriction injury (CCI) rats. Proc Am Pain Soc, 2004. 